\title{
Validity of Anthropometric Cut-offs for Early Diagnosis of Dyslipidemia among Adults in Jimma Town, Southwest Ethiopia
}

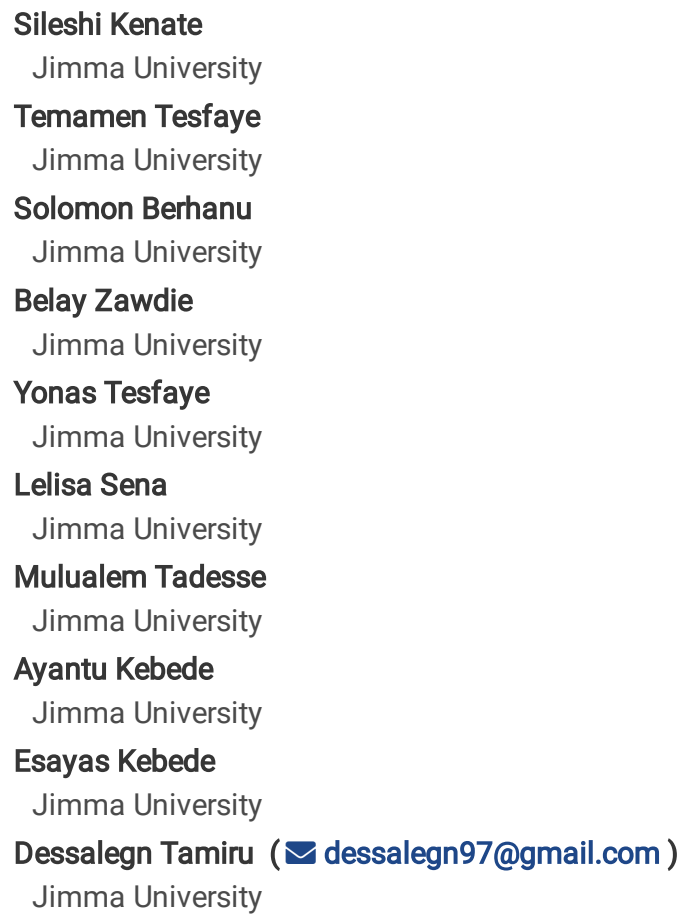




\section{Abstract}

Background: Lack of regional and local based cut off points of lipid profile and/or anthropometric measurement remains one of the challenges in prevention, early detection and control of non-communicable diseases. This study was aimed to validate anthropometric based screening of lipid profile in order to prevent potential predictors of major non-communicable diseases.

Methods: Community based cross sectional study was conducted among randomly selected 977 adults in Jimma Town, Ethiopia from July 20 to August 20, 2019. Data were collected using structured questionnaire, anthropometric and biochemical measurements. Data were analyzed using SPSS windows version 20 and Kappa statistic $(K)$ was used to validate the agreement between anthropometric measurement and lipid profile of the study participants. A p-value of $<0.05$ was considered statistically significant.

Results: Body mass index (BMI) at $\geq 24.5$ was used as screening of dyslipidemia ( $T G \geq 150 \mathrm{mg} / \mathrm{dl})$ with slight Kappa coefficient of 0.138 ( $<<0.001$ ) among females while it was $\geq 22.2$ among males with fair $(0.275)$ Kappa coefficient $(P<0.001)$. Waist circumference based screening of dyslipidemia ( $T G \geq 150 \mathrm{mg} / \mathrm{dl})$ at $\geq 78.0 \mathrm{~cm}$ had negative $(-0.005)$ Kappa coefficient $(\mathrm{P}<0.001)$ among females (sensitivity: $72.6 \%$ \& specificity: $26.7 \%)$. Yet, waist circumference at $\geq 83.7 \mathrm{~cm}$ had slight Kappa coefficient of $0.13(\mathrm{P}<0.005)$ among males (sensitivity: $38 \%$ \& specificity: $74.9 \%)$. Waist hip ratio based screening of dyslipidemia ( $T G \geq 150 \mathrm{mg} / \mathrm{dl})$ at $\geq 0.82$ among females had negative $(-0.001) \mathrm{Kappa}$ coefficient ( $\mathrm{p}=0.763)$ whereas among males at $\geq 0.88$ there was a slight ( 0.105$)$ Kappa coefficient of $(p=0.002)$ (Sensitivity: $77.5 \%$ \& Specificity: $36.8 \%$ ). This study showed that anthropometric based of high-density lipoprotein measurement was not applicable.

Conclusions: Findings of this study indicated that BMI-based screening of triglyceride was applicable for both sexes than other anthropometric measurements. Waist circumference and Waist to hip ratio-based screening of triglyceride was slightly applicable only for males. However, anthropometric based screening of high-density lipoprotein measurement was not applicable for both sexes. In conclusion, researchers and policy makers need to consider local cut off points to conduct screening nutritional status of the community.

\section{Introduction}

Metabolic syndrome is a subset of non-communicable diseases (NCDs), which is interconnected by physiological, biochemical, clinical and metabolic factors that directly increases the risk of cardiovascular disease and type 2 diabetes mellitus. Insulin resistance, visceral adiposity, atherogenic dyslipidemia, endothelial dysfunction, genetic susceptibility, elevated blood pressure, hypercoagulable state and chronic stress are among several factors which constitute the syndrome (1). Individuals with metabolic syndrome exhibit a characteristic pattern of abnormalities in serum lipid levels consisting of a low level of high density lipoprotein and an elevated level of triglyceride (2).

Different studies show that the burdens of NCDs on health of the population and health services have been increased in developing countries. Cardiovascular diseases, cancer, chronic respiratory diseases and diabetes are responsible for $82 \%$ of deaths. Currently, low income countries are witnessing epidemiological transition from infectious communicable diseases to chronic non-communicable diseases due to changes in the life styles, rapid urbanization and diminishing levels of physical activity (4). Consequently, non-communicable diseases are predicted to increase globally by $17 \%$ and by $27 \%$ in the African region in the next 10 years and projected to overtake communicable diseases as the major cause of morbidity in sub-Saharan Africa by the year 2030 (3).

The report of 2017 WHO progress monitor also showed that NCDs kill 41 million people each year, which is $71 \%$ of all global deaths. In Ethiopia, the proportion of death from NCDs has been reported to $42 \%$ of all causes of deaths, which accounts $27 \%$ of premature deaths before the age 70 years (5). The increment of NCDs on top of the preexisting highly prevalent communicable diseases, maternal, prenatal and nutritional conditions constrains the already meager health resources and hinders economic development of the country (6).

However, it is only relatively recent that the NCDs have received attention in low-income countries. Consequently, unrecognized/undiagnosed NCDs are found to be major problems as the individuals are unaware of their status in this regard. It has been indicated that the international anthropometric cutoff or detecting obesity is not appropriate for Ethiopians (7). There is a need to re-orient the national health system to ensure recognition of the NCDs burden and improve organization and delivery of NCDs services at primary health care (PHC) level $(8,9)$.

Lack of local based cut off points remains one of the challenges in management, prevention, control of NCDs and their modifiable risk factors. Optimal anthropometric cut-offs for detecting obesity and markers of metabolic syndrome in Ethiopian adults are lower than the international cutoffs for waist circumference, waist to hip ratio and body mass index underestimate obesity and metabolic syndrome markers. Therefore, developing standardized local cut off points for the measurement of NCDs is crucial for prevention and management of NCDs by early detection. Thus, this study aimed to validate anthropometric measurements cut off points among Ethiopian adults (7) in order to screen at household level by using waist circumference, waist to hip ratio and BMI measurement in Jimma Town, Oromia Regional State, Southwest Ethiopia.

\section{Methods}


Community based cross sectional study was conducted in Jimma Town from June to July 2019 among adults aged $\geq 18$ years. Jimma is found in Southwest Ethiopia, located at $352 \mathrm{~km}$ from capital city of Addis Ababa. Sample size was calculated using sensitivity estimation formula taking highest prevalence of high density lipoprotein (23.4\% ) based on a study done in Addis Ababa among Ethiopian adults (11), $5 \%$ margin of error, $95 \%$ confidence level and $90 \%$ an anticipated sensitivity (7). Finally, 977 sample size was calculated by considering $10 \%$ non-response rate and 1.5 design effects. Study participants were selected using two-stage cluster sampling technique. Six kebeles (smallest administrative unit) out of 17 were randomly selected. Study participants were selected from each kebele proportionally based on the number of households in each selected kebele using systematic sampling technique methods.

\section{Inclusion and Exclusion Criteria}

All residents who lived in the town for six months prior the data collection was included into the study. However, adults who had physical deformity (kyphosis and sclerosis), pregnancy, known chronic illness and seriously ill were excluded.

\section{Data Collection Procedure}

Data were collected using WHO stepwise questionnaire and adapted to the local context. A survey tools include socio-demographic characteristics, anthropometric measurements and laboratory analyses of lipid profile formats. Height of the study participants was measured to the nearest 0.1 cm using a stadiometer (seca Germany) with the subjects positioned at the Frankfurt Plane and the four points (heel, calf, buttocks and shoulder) touching the vertical stand and their shoes taken off. Before starting the measurements, the stadiometer was checked using calibration rods. Weight was measured using digital weight scale to the nearest $0.1 \mathrm{~kg}$ with the subjects wearing light closes and shoes taken off. The validity of the scale was checked using an object of a known weight of $1 \mathrm{~kg}$.

Waist circumference was measured at midpoint between the inferior margin of the last rib and the iliac crest just at wider area using a stretch tape. Just before taking the measurement, participants were requested to stand with their feet together, place their arms at their side of their body with the palms of their hands facing inwards, and breathe out gently. Hip circumference was measured at the level of the greater trochanter of the femur with the subjects wearing a pant. All anthropometric measurements were done in triplicate and the average value was used for further analysis. Standardization of anthropometric measurers were done to reduce inter observer error.

The laboratory parameter was determined according to the standard operating procedures. Five 5 ml venous blood was collected to determine participant's lipid profiles in mg/dl. Serum was carried out in ABX Pentra 400 Automated Chemistry Machine (Horiba ABX SAS, 34184 Montpellier(12) at Jimma medium Clinical chemistry Core laboratory to determine lipid profile including total cholesterol, high-density lipoprotein (HDL) and triglyceride (TAG). Low density lipoprotein level was calculated by using Freidwald formula (13).

The optimal cut-off values of waist circumference (WC) was $85.3 \mathrm{~cm}$ for male and $78.0 \mathrm{~cm}$ for females and the values greater than this indicates risk factor for obesity. The optimal cut-off values of waist to hip ratio (WHR) were calculated by dividing waist to hip in centimeters. The cut off values were $0.88 \mathrm{~cm}$ to male and $0.82 \mathrm{~cm}$ for females; values greater than the cut off value was considered at risk for obesity. Similarly the optimal cut-off of values body mass index (BMI) was $24.5 \mathrm{~kg} / \mathrm{m}^{2}$ for female and $22.2 \mathrm{~kg} / \mathrm{m}^{2} \mathrm{for}$ male; values greater than the cut off value was considered as at risk for obesity. A lipid level was classified according to WHO classification and triglyceride was considered as normal when it was $<150 \mathrm{mg} / \mathrm{dl}$ and HDL-C was considered as normal if it is $>40 \mathrm{mg} / \mathrm{dl}$ male and $>50 \mathrm{mg} / \mathrm{dl}$ for female (14).

\section{Data Quality Management}

Data collectors were trained for five days before the actual data collection on interviewing approach, anthropometric measurement and data recording. To ensure the quality of the data, properly designed data collection instrument was used. Calibration of instruments was done to increase the reliability of the measurements. A questionnaire for the survey was first prepared in English language and translated into local languages (Afan-Oromo and Amharic), then translated back into English to check for consistency. The questionnaire was pre-tested on $5 \%$ of sample size in Agaro Town and based on the pretest, additional adjustment was made on terminologies.

\section{Data Processing and Analysis}

Data were checked for completeness. The data was cleaned and checked for outliers and missing values. Epi Data version 3.1 and SPSS version 21 were used for data entry and analysis, respectively. The data were checked for normality using QQ-plot. Descriptive analysis was used to describe the study subjects and presented using tables and figures. Validity measures including sensitivity, specificity, positive predictive value, negative predictive values and Kappa agreement were determined to validate anthropometric based screening of lipid profile.

\section{Results}

A total of 915 individuals were interviewed with a $93.7 \%$ response rate. The mean age of study participants was $38.35 \pm 13.51$ years. Large proportion of the respondents (71.5\%) was married. Majority of participants were Oromo ethnic (66.0\%) and Muslim followers (56.0\%). Closely 
three-fourth (64.5\%) of the study participants attended at least primary school (Table 1).

Table 1

The socio-demographic characteristics of adults in Jimma town, Ethiopia

\begin{tabular}{|c|c|c|c|}
\hline Variable & Categories & Number (n) & Percent (\%) \\
\hline \multirow[t]{2}{*}{ Sex } & Male & 476 & 52.0 \\
\hline & Female & 439 & 48.0 \\
\hline \multirow[t]{4}{*}{ Age } & $\leq 30$ & 323 & 35.3 \\
\hline & $31-40$ & 301 & 32.9 \\
\hline & $41-50$ & 126 & 13.8 \\
\hline & $\geq 51$ & 165 & 18.0 \\
\hline \multirow[t]{5}{*}{ Educational status } & Degree and Above & 79 & 8.6 \\
\hline & Diploma & 96 & 10.5 \\
\hline & Illiterate & 150 & 16.4 \\
\hline & Primary School & 377 & 41.2 \\
\hline & Secondary School & 213 & 23.3 \\
\hline \multirow[t]{5}{*}{ Marital Status } & Single & 130 & 14.2 \\
\hline & Married & 654 & 71.5 \\
\hline & Divorced & 79 & 8.6 \\
\hline & Widowed & 40 & 4.4 \\
\hline & Separated & 12 & 1.3 \\
\hline \multirow[t]{4}{*}{ Religion } & Orthodox & 290 & 31.7 \\
\hline & Muslim & 512 & 56.0 \\
\hline & Protestant & 111 & 12.1 \\
\hline & Catholic and Wakefata & $2(0.2)$ & $2(0.2)$ \\
\hline \multirow[t]{6}{*}{ Ethnic Group } & Oromo & 604 & 66.0 \\
\hline & Amhara & 81 & 8.9 \\
\hline & Dawuro & 97 & 10.6 \\
\hline & Yemi & 30 & 3.3 \\
\hline & Gurage & 33 & 3.6 \\
\hline & Others* & 70 & 7.7 \\
\hline \multirow[t]{8}{*}{ Occupation } & Unemployed & 117 & 12.8 \\
\hline & Student & 41 & 4.5 \\
\hline & Housewife & 158 & 17.3 \\
\hline & Daily laborer & 124 & 13.6 \\
\hline & Merchant & 81 & 8.9 \\
\hline & Government Employee & 183 & 20.0 \\
\hline & Private employee & 133 & 14.5 \\
\hline & Others $^{+}$ & 78 & 8.5 \\
\hline
\end{tabular}


Body mass index-based screening of Triglyceride in both sexes had slight Kappa agreement among female and fair agreement among males. Using BMI at $\geq 24$ for screening of hyper triglyceride ( $T G \geq 150 \mathrm{mg} / \mathrm{dl})$ among females had slight $(0.12)$ Kappa agreement $(P=0.024)$ with $72.6 \%$ sensitivity and $65.0 \%$ specificity. Similarly, in case of male, BMI at $\geq 22.2 \mathrm{~kg} / \mathrm{m}^{2}$ based screening of dyslipidemia (TG $\geq 150 \mathrm{mg} / \mathrm{dl}$ ) had fair (0.275) Kappa agreement ( $P<0.001)$ with $64.1 \%$ sensitivity and $66.8 \%$ specificity. Body mass index-based screening of high-density lipoprotein (HDL-C $<50 \mathrm{mg} / \mathrm{dl}$ ) among females at $\geq 24.5 \mathrm{~kg} / \mathrm{m}^{2}$ had negative $(-0.003)$ Kappa coefficient with $58.0 \%$ sensitivity and $41.7 \%$ specificity, which is not statistically significant $(p=0.949)$. Similarly, BMI at $\geq 22.2 \mathrm{~kg} / \mathrm{m}^{2}$ had a slight $(0.032)$ Kappa coefficient $(P=0.449)$ with $58.1 \%$ sensitivity and $45.45 \%$ specificity (Table 2$)$.

Table 2

Comparison of BMI based screening of triglyceride and HDL with laboratory results among Jimma town adults

\begin{tabular}{|c|c|c|c|c|c|c|c|c|c|c|c|c|c|}
\hline \multicolumn{4}{|c|}{ BMI based screening } & \multicolumn{10}{|c|}{ Laboratory Results } \\
\hline Marker & Sex & $\begin{array}{l}\text { Cut } \\
\text { off } \\
\text { point }\end{array}$ & $\mathrm{TP}(\mathrm{a})$ & $\mathrm{FP}(\mathrm{b})$ & $\mathrm{FN}(\mathrm{c})$ & $\mathrm{TN}(\mathrm{d})$ & Total(P) & $\begin{array}{l}\text { Sensitivity } \\
\text { (\%) }\end{array}$ & $\begin{array}{l}\text { Specificity } \\
(\%)\end{array}$ & PPV & NPV & Kappa & $\mathrm{P}$ \\
\hline \multirow[t]{2}{*}{$\begin{array}{l}T G \geq \\
150\end{array}$} & $\mathrm{~F}$ & $\begin{array}{l}\mathrm{BMI} \geq \\
24.5\end{array}$ & 53 & 114 & 60 & 212 & 439 & 72.6 & 65 & 32 & 83 & 0.12 & $\begin{array}{l}<.001 \\
0.001\end{array}$ \\
\hline & $M$ & $\begin{array}{l}\mathrm{BMI} \geq \\
22.2\end{array}$ & 86 & 101 & 56 & 233 & 476 & 64.1 & 66.8 & 45 & 81 & 0.275 & $\begin{array}{l}< \\
0.001\end{array}$ \\
\hline $\begin{array}{l}\mathrm{HDL}< \\
50\end{array}$ & $\mathrm{~F}$ & $\begin{array}{l}\mathrm{BMI} \geq \\
24.5\end{array}$ & 160 & 95 & 116 & 68 & 439 & 58 & 41.7 & 63 & 37 & -0.003 & 0.949 \\
\hline $\begin{array}{l}\mathrm{HDL}< \\
40\end{array}$ & $M$ & $\begin{array}{l}\mathrm{BMI} \geq \\
22.2\end{array}$ & 104 & 162 & 75 & 135 & 476 & 58.1 & 45.5 & 39 & 64 & 0.032 & 0.449 \\
\hline
\end{tabular}

Waist circumference based screening of dyslipidemia (TG $\geq 150 \mathrm{mg} / \mathrm{dl}$ ) at $\geq 78.0$ among females had - $0.005 \mathrm{Kappa}$ coefficient with $72.6 \%$ sensitivity and $26.7 \%$ specificity, which was not statistically significant $(p=0.877)$. On the other hand, for males, waist circumference at $>=$ $83.7 \mathrm{~cm}$ based screening of dyslipidemia ( $T \mathrm{G} \geq 150 \mathrm{mg} / \mathrm{dl})$ had slight Kappa agreement of $0.13(\mathrm{p}=0.005)$ with $38.0 \%$ sensitivity and $74.9 \%$, specificity.

Waist circumference based screening of high-density lipoprotein cholesterol (<50 mg/dl) at $\geq 78.0 \mathrm{~cm}$ had slight Kappa coefficient ( 0.04$)$ with $27.5 \%$ sensitivity and $77.3 \%$, specificity which was not statistically significant $(p=0.263)$. Similarly, for male waist circumference $\geq 83.7 \mathrm{~cm}$ based screening of HDL-C had slight Kappa coefficient of 0.02 , but not statistically significant (Table 3 ).

Table 3

Comparison of waist circumference based screening of triglyceride and HDL with laboratory results among adults, Jimma Town

\begin{tabular}{|c|c|c|c|c|c|c|c|c|c|c|c|c|c|}
\hline \multicolumn{3}{|c|}{ WC Based Screening } & \multicolumn{11}{|c|}{ Laboratory Results } \\
\hline Markers & Sex & $\begin{array}{l}\text { cut off } \\
\text { value }\end{array}$ & $\mathrm{TP}(\mathrm{a})$ & $\mathrm{FP}(\mathrm{b})$ & $\begin{array}{l}\mathrm{FN} \\
\text { (c) }\end{array}$ & $\mathrm{TN}(\mathrm{d})$ & $\begin{array}{l}\text { Total } \\
(\mathrm{P})\end{array}$ & $\begin{array}{l}\text { Sensitivity } \\
(\%)\end{array}$ & $\begin{array}{l}\text { Specificity } \\
(\%)\end{array}$ & PPV & NPV & Kappa & $P$ \\
\hline \multirow{2}{*}{$\begin{array}{l}T G \geq \\
150\end{array}$} & $\mathrm{~F}$ & $W C \geq 78$ & 82 & 239 & 31 & 87 & 439 & 72.6 & 26.7 & 25.5 & 73.7 & -.005 & 0.877 \\
\hline & $M$ & $W C \geq 83.7$ & 54 & 84 & 88 & 250 & 476 & 38.0 & 74.9 & 39.1 & 73.9 & 0.13 & 0.005 \\
\hline $\begin{array}{l}\mathrm{HDL}< \\
50\end{array}$ & $\mathrm{~F}$ & $W C \geq 78$ & 76 & 37 & 200 & 126 & 439 & 27.5 & 77.3 & 67.3 & 38.7 & 0.04 & 0.263 \\
\hline $\begin{array}{l}\mathrm{HDL}> \\
40\end{array}$ & $M$ & $W C \geq 83.7$ & 54 & 84 & 125 & 213 & 476 & 30.2 & 71.7 & 39.1 & 63.0 & 0.02 & 0.661 \\
\hline
\end{tabular}

Waist circumference to hip ratio based screening of triglyceride was valid only for male at $\geq 0.88 \mathrm{~cm}$ with slight (0.105) Kappa coefficient ( $p=$ 0.002 ) and $77.46 \%$ sensitivity and $36.83 \%$ specificity. However, in case female, WHR at $\geq 0.82 \mathrm{~cm}$ was not statistically significant. WHR based screening of high-density lipoprotein cholesterol was not statistically significant for both female $(p=0.263)$, and male $(p=0.661)($ Table 4$)$. 
Table 4

Comparison of WHR based screening of triglyceride and HDL with laboratory results among adults, Jimma Town

\begin{tabular}{|c|c|c|c|c|c|c|c|c|c|c|c|c|c|}
\hline \multicolumn{3}{|c|}{ WHR based screening } & \multicolumn{11}{|c|}{ Laboratory Results } \\
\hline Markers & sex & $\begin{array}{l}\text { cut off } \\
\text { value }\end{array}$ & $\mathrm{TP}(\mathrm{a})$ & $\mathrm{FP}(\mathrm{b})$ & $\mathrm{FN}(\mathrm{c})$ & $\mathrm{TN}(\mathrm{d})$ & Total $(\mathrm{P})$ & $\begin{array}{l}\text { Sensitivity } \\
(\%)\end{array}$ & $\begin{array}{l}\text { Specificity } \\
(\%)\end{array}$ & PPV & NPV & Kappa & $\mathrm{P}$ \\
\hline \multirow[t]{2}{*}{$\begin{array}{l}\text { TG } \geq \\
150\end{array}$} & $\mathrm{~F}$ & $\begin{array}{l}\text { WHR } \geq \\
0.82\end{array}$ & 112 & 324 & 1 & 2 & 439 & 99.12 & 0.613 & 25.7 & 66.7 & -0.001 & 0.763 \\
\hline & $M$ & $\begin{array}{l}\text { WHR } \geq \\
0.88\end{array}$ & 110 & 211 & 32 & 123 & 476 & 77.46 & 36.83 & 34.3 & 79.4 & 0.105 & 0.002 \\
\hline $\begin{array}{l}\mathrm{HDL}< \\
50\end{array}$ & $\mathrm{~F}$ & $\begin{array}{l}\text { WHR } \geq \\
0.82\end{array}$ & 274 & 162 & 2 & 1 & 439 & 99.28 & 0.613 & 62.84 & 33.3 & -.001 & 0.891 \\
\hline $\begin{array}{l}\mathrm{HDL}< \\
40\end{array}$ & $M$ & $\begin{array}{l}\text { WHR } \geq \\
0.88\end{array}$ & 137 & 223 & 42 & 74 & 476 & 76.5 & 24.9 & 38.1 & 638 & 0.012 & 0.721 \\
\hline
\end{tabular}

\section{Discussion}

Developing locally appropriate optimal cut-off points using obesity based anthropometric measurement is important for early detection of metabolic syndrome to prevent farther complication and disabled from unrecognized NCD(7). According to the present study, BMI based screening of triglyceride had fair and slight agreement of Kappa coefficient among males and females, respectively. A similar study done in Brazil also revealed that anthropometric indices had slight differences in screening of triglyceride among males and females. It also revealed that BMI based screening of triglyceride was applicable when compared with other anthropometric measurements (15). Likewise, other hospital based studies done in India and Canada indicated weak correlation between body mass index (BMI) and lipid profiles $(16,17)$. There is also another study, which showed that BMI based screening for dyslipidemia was applicable (18).

Waist circumference based screening of triglyceride among males showed slight agreement $(k=0.13)$. However, similar studies from Canada and India found that waist circumference was a better predictor of dyslipidemia (TG) in both sexes $(17,19,20)$. Similar to waist circumference, the screening of triglyceride based on wait to hip ratio among males had slight Kappa agreement $(k=0.105)$, which is statistically significant $(p=$ 0.002). Study done in India among adult population ( $\leq 60$ years old) and aged group of population in Brazil (60 years old and above) revealed that anthropometric indices of waist to hip ratio was the best indicators for screening dyslipidemia $(T G)(15,21)$. This discrepancy might be due to the difference in sample size, age difference or ethnic differences, which can be addressed by a large scale and multi-centered study involving different populations.

\section{Conclusion}

Anthropometric indices can be used as a simple screening of dyslipidemia at primary health care unit. Body mass index cut of points at $\geq$ $24.5 \mathrm{~kg} / \mathrm{m}^{2}$ for females and $\geq 22.2 \mathrm{~kg} / \mathrm{m}^{2}$ for males can be used for screening of dyslipidemia (TG $\geq 150 \mathrm{mg} / \mathrm{dl}$ ). Similarly, waist circumference at $\geq 83.7 \mathrm{~cm}$ and waist to hip ratio at $\geq 0.88$ can be considered as screening of dyslipidemia (TG $\geq 150 \mathrm{mg} / \mathrm{dl}$ ) among males. Generally with further investigation health facilities and researchers can use anthropometric indices as alternative to investigate lipid profiles to prevent nutrition related non-communicable diseases.

\section{Abbreviations}

\section{TG}

Triglycerides, WC:Waist Circumference, WHR:Waist to Hip Ratio

\section{Declarations}

\section{Ethics approval and consent to participate}

Ethical approval and clearance were obtained from Jimma University Ethical Review Board. Verbal consent was taken from each study subjects after clear disclosure of the study objective. The privacy of patients was respected and results regarding the participants made confidential.

\section{Consent for publication}

Not applicable. 
The data set used for this study can be shared based on a reasonable request.

\section{Competing interests}

The authors declare that they have no competing interests.

\section{Funding}

The authors received no financial support for the publication of the article.

\section{Authors' contributions}

The authors' responsibilities: All authors had the primary responsibility for the content and finally submitted the paper for publication. All authors read and approved the final manuscript.

\section{Acknowledgements}

The authors would like to express their gratitude to Jimma University for facilitating this study. We would also like to thank study participants who gave valuable information.

\section{References}

1. Kaur J. A Comprehensive Review on Metabolic Syndrome. Cardiol Res Pract. 2014;1-22.

2. Brinck J, Thomas A, Lauer E, Jornayvaz F, Brulhart-Meynet M, Prost J, Pataky Z, Löfgren P, Hoffstedt J, Eriksson M, Pramfalk C, Morel S, Kwak B, van Eck M, James R, Frias M. Diabetes Mellitus Is Associated With Reduced High-Density Lipoprotein Sphingosine-1-Phosphate Content and Impaired. Arterioscler Thromb Vasc Biol. 2016;36(5):817-24.

3. World Health Orgnaztion. Global Report On Diabetes. 2016; https://apps.who.int/iris/bitstream/10665/204871/1/9789241565257_eng.pdf.

4. Kavishe B, Biraro S, Baisley K, Vanobberghen F, Kapiga S, Munderi P, Smeeth L, Peck R, Mghamba J, Mutungi G, Ikoona E, Levin J, Maria Monclús A, Katende D, Kisanga E, Hayes R, Grosskurth $\mathrm{H}$. High prevalence of hypertension and of risk factors for non-communicable diseases (NCDs): a population based cross-sectional survey of NCDS and HIV infection in Northwestern Tanzania and Southern Uganda. BMC Med. 2015;13:126.

5. Shiferaw F, Letebo M, Misganaw A, Feleke Y, Gelibo T, GetachewT, Defar A, Assefa A, Bekele A, Amenu K, Teklie H, Tadele T, Taye G, Getnet M, Gonfa G, Bekele A, Kebede T, YadetaD, GebreMichael M, Challa F, Girma Y, Mudie K, Guta M, Tadesse Y. Non-communicable Diseases in Ethiopia: Disease burden, gaps in health care delivery and strategic directions. Ethiop. J. Health Dev. 2018;32(3).

6. Misganaw A, Haregu T, Deribe K, Tessema G, Deribew A. National mortality burden due to communicable, non-communicable, and other diseases in Ethiopia, 1990-2015 : findings from the Global Burden of Disease Study 2015. Popul Health Metr. 2017;15:29.

7. Sinaga M, Worku M, Yemane T, Tegene E, Wakayo T, Girma T, Lindstrom D, Belachew T. Optimal cut-off for obesity and markers of metabolic syndrome for Ethiopian adults. Nutr J. 2018;17:109.

8. Federal Democratic Republic of Ethiopia. The Ethiopia Noncommunicable Diseases and Injuries (NCDI) Commission Report Summary: Addressing the Impact of Noncommunicable Diseases and Injuries in Ethiopia. https://static1.squarespace.com/static/55d4de6de4b011a1673a40a6/t/5bfc17ab 21c67c558106119e/15432 47788342/Ethiopia + NCDI + Commission + Report + Summary + FINAL.pdf.

9. Asfaw D, Teshome E. Tobacco control and prevention efforts in Ethiopia pre- and post-ratification of WHO FCTC: Current challenges and future directions. Tob Induc Dis. 2019;17:13.

10. Sorana D. Medical Diagnostic Tests: A Review of Test Anatomy, Phases, and Statistical Treatment of Data. Comput Math Methods Med. 2019; 2019: 1891569.

11. Gebreyes Y, Goshu D, Geletew T, Argefa T, Zemedu T, Lemu KA, et al. Prevalence of high bloodpressure, hyperglycemia, dyslipidemia, metabolic syndrome and their determinants in Ethiopia. PLoS ONE 13 (5): e0194819.

12. GreenSebastian R, Wachsmann-Hogiu W. Development, History, and Future of Automated Cell Counters. Clin Lab Med. 2015;35(1):1-10.

13. KarimollahHajian-Tilaki. Sample size estimation in diagnostic test studies of biomedical informatics. J Biomed Inform. 2014;48:193-204;.

14. Sinaga M, Yemane T, Tegene E, Lidstrom D, Belachew T. Performance of newly developed body mass index cut-off for diagnosing obesity among Ethiopian adults. J Physiol Anthropol. 2019;38:14. 
15. Silva R, FaresII D, Rodrigues A, Dél T. Matos W,Henrique M. Anthropometric indicators as predictors of serum triglycerides and hypertriglyceridemia in older adults. MedicalExpress. 2014;1:4.

16. Manjareeka M, Nanda S, Mishra J, Mishra S. Correlation between anthropometry and lipid profile in healthy subjects of Eastern India. J Midlife Health. 2015;6(4):164-8.

17. Brenner D, Tepylo K, Eny K, Cahill L, El-Sohemy A. Comparison of body mass index and waist circumference as predictors of cardiometabolic health in a population of young Canadian adults. Diabetol Metab Syndr. 2010; 12;2(1):28.

18. Ramoteme L, Martinique S, Sarah J, Makama A. The association between dyslipidemia and anthropometric indicators in black and white adolescents residing in Tlokwe Municipality, North-West Province, South Africa: the PAHL study. Afr Health Sci. 201; 14(4): 929-938.

19. Rao S, Parab-Waingankar P. Performance of waist circumference relative to BMI in predicting risk of obesity and hypertension among affluent Indian adults. Health. 2013;05(08):16-22.

20. Silvana C, Miralles W, Wollinger LM, Marin D, Genro JP, Contini V, et al. Waist-to-height ratio (WHtR) and triglyceride to HDL-c ratio ( TG / HDL-C ) as predictors of cardiometabolic risk. Nutr Hosp. 2015;31(5):2115-21.

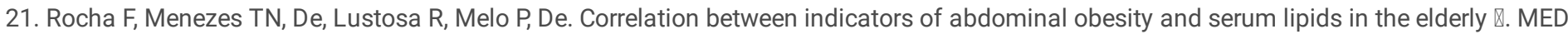
BRAS. 2013;59:48-55. 